\title{
Detection and location of places of spontaneous combustion of coal in mines due to gas anomalies on the earth's surface
}

\author{
Vyacheslav Portola ${ }^{1, *}$, Alyona Bobrovnikova ${ }^{2}$, Georgii Shirokolobov ${ }^{3}$, and Dmitiy Paleev ${ }^{4,5}$ \\ ${ }^{1}$ T.F. Gorbachev Kuzbass State Technical University, Department of an aerology, labor protection \\ and nature, 650000 Kemerovo, 28 Vesennya st., Russian Federation \\ ${ }^{2}$ T.F. Gorbachev Kuzbass State Technical University, Department of chemistry, technology of \\ inorganic substances and nanomaterials, 650000 Kemerovo, 28 Vesennya st., Russian Federation \\ ${ }^{3}$ T.F. Gorbachev Kuzbass State Technical University, Department of building structures, water \\ supply and sanitation, 650000 Kemerovo, 28 Vesennya st., Russian Federation \\ ${ }^{4}$ Federal State Institution "National Rescue Center" Ministry of Emergency Situations of Russia, \\ 654044, Novokuznetsk, Prospect Aviatorov, 54, Russian Federation \\ ${ }^{5}$ Mining Institute of the Ural Branch of the Russian Academy of Sciences, 614007, Perm, Siberian \\ Str., 78a, Russian Federation
}

\begin{abstract}
The effectiveness of localization and extinguishing of places of underground fires that occur in mine worked out spaces depends on information about the location of a place of spontaneous combustion. Existing methods to detect the processes of coal spontaneous combustion in mines include monitoring the content of gases in mine atmosphere, released during the spontaneous combustion of coal. However, this control method does not allow determining the location of a place of combustion, since the paths of gas movement in the worked out space are unknown. The surface gas survey allows to determine the location of the underground fire. The calculations showed that gases, generated in the fire seat, spread to the earth's surface due to molecular diffusion, the thermal depression developed by the fire seat and the drops of air pressure created by the ventilation fans. The dependences of the distribution of fire gases content in rocks on the rate of drops of air pressure between the worked out space in a mine with a fire seat and the atmosphere on the surface of the earth are obtained. Mine researches have confirmed the formation of anomalies of fire gases in rocks and soil over places of spontaneous combustion of coal occurred in worked out space. When conducting a gas survey, it is sufficient to measure the content of fire gases in the soil at a depth of 0.5$1.0 \mathrm{~m}$.
\end{abstract}

\section{Introduction}

Underground coal mining is potentially dangerous because of dangerous effects and harmful factors on miners, as well as the possibility of accidents. The most common

${ }^{*}$ Correspondent author: portola2@yandex.ru 
accidents at Kuzbass coal mines are underground fires. Endogenous fires, the cause of which is coal spontaneous combustion, cause especially great economic damage to mines. Most often spontaneous combustion processes develop in the worked out space in mines. Extinguishing of such fires is difficult due to the lack of information about the location of a fire seat. The danger of places of spontaneous combustion is in the release of toxic gases into the mine atmosphere and the possibility of ignition of explosive mixtures of combustible gas and coal dust. Thus, a number of works [1-9] are devoted to the study of features of the process of coal spontaneous combustion, in which factors affecting the development of endogenous fires are analysed.

The efficiency of extinguishing of places of coal spontaneous combustion in worked out mines is largely determined by the ability to detect the process of spontaneous combustion at an early stage of development and the accuracy to determine the fire location. A gasanalytical method is widely used in mines, which makes it possible to detect the process of coal spontaneous combustion by the content of combustion products in the mine atmosphere (carbon oxide, hydrogen, saturated and unsaturated hydrocarbons). To detect fires in mines, stationary and portable gas analysers are used. In addition to fire gases, to detect the early stage of the spontaneous combustion process, it was proposed to use condensed liquid particles that arise in the air after they pass the fire seat [10]. In most works [11-15] the behaviour of gases during movement and their absorption by rocks formed because of spontaneous combustion of coal is considered. However, this method does not allow to fix the location of the fire seat, since there is no information on the path of filtering air leaks in the worked out space.

It is possible to use the gases generated in a spontaneously combustible accumulation of coal to locate the seat of underground fire, if the content of these gases is controlled not in the mine, but in the soil above the abandoned coal seam. Thus, the air density in the fire seat decreases and the convective fluxes generated by the thermal depression carry fire gases to the earth's surface. Therefore, to locate places of spontaneous combustion on the earth's surface, not only fire gases, but also radon, the concentration of which can be increased in the atmosphere of the worked out space, can be used [16]. The transfer of gases to the surface is facilitated by an increase in the permeability of the undermined rocks, as well as the excess air pressure in the mine that occurs during the injection method of ventilation. However, the suction ventilation method will prevent the escape of gases to the surface. Therefore, it is necessary to evaluate the conditions that allow the usage of surface gas surveys to determine the location of underground places of spontaneous combustion.

\section{Results and Discussion}

The removal of fire gases from the worked out space to the surface is mainly due to the excess gas pressure in the fire seat, arising because of the ventilation fans operation and the molecular diffusion of the gases generated during coal spontaneous combustion. Thermal depression developed by the fire seat is equally important for the formation of convective gas flows to the surface. With suction and pressure-suction methods for ventilating mines, this factor can have a decisive effect on the movement of tracer gases generated in the fire seat to the earth's surface. A significant role in the removal of gases from the worked out space to the earth's surface can be played by fluctuations in atmospheric pressure and natural temperature differences on the surface. Moreover, the study of the influence of these parameters on the process of removal of fire gases is especially important, since under the influence of these factors sudden appearance of gases on the surface dangerous to human life is possible. 
To assess the possibility of using surface gas surveys to detect and locate spontaneous combustion areas, it is necessary to study the parameters of the concentration fields of gases generated in the fire seat. The distribution of fire gases from the fire seat to the surface can be described with a stationary one-dimensional equation. The transfer of gases formed in the fire seat occurs due to molecular diffusion and the air flow moving due to the drops of air pressure. The reason of the difference in air pressure between the worked out space with the fire seat and the earth's surface may be the operation of ventilation fans and the thermal depression developed by the fire. In this case, the mass transfer equation has the following form

$$
P D \frac{d^{2} C}{d x^{2}}-v \frac{d C}{d x}=0
$$

where $\mathrm{P}$ is the porosity of the rocks; $\mathrm{D}$ is the coefficient of molecular diffusion of the gas, $\mathrm{m}^{2} / \mathrm{s}$; $\mathrm{C}$ is the fire gas concentration, a fraction of a unit; $\mathrm{v}$ - air filtration rate in the rocks, $\mathrm{m} / \mathrm{s}$.

The air filtration rate between the area with the fire seat and the earth's surface can be calculated by the formula

$$
v \frac{\Delta P K}{\mu L}
$$

where $\Delta \mathrm{P}$ is the drop of pressure of the gas between the worked out space and the earth's surface, $\mathrm{Pa} ; \mathrm{K}$ is rock permeability coefficient, $\mathrm{m}^{2}$; $\mathrm{L}$ is the distance from the fire area to the earth's surface, $\mathrm{m}$; is gas viscosity, $\mathrm{kg} /(\mathrm{m} \cdot \mathrm{s})$.

When solving equation (1), the boundary conditions were used

$$
C(x=0)=C_{0} \quad C(x=L)=0,
$$

where $\mathrm{C}_{0}$ is the concentration of fire gas in the source, a fraction of a unit; $\mathrm{L}$ is the distance from the source to the surface, $\mathrm{m}$.

Solving equation (1) under boundary conditions (3), we obtain the following expression for determining the concentration of gases released in the fire seat in the overlying rock

$$
C(x)-C_{0}\left[\frac{\exp \left(\frac{v L}{D P}\right)-\left(\exp \frac{v x}{D P}\right)}{\exp \left(\frac{v L}{D P}\right)-1}\right]
$$

The removal of indicator gases to the surface is facilitated by the formation of collapse zones and cracks over the worked out coal seam. The size of the disturbed area depends on the removed capacity of the seam, mp. So, the height of the collapse zone is $(3-6) \mathrm{mp}$, the region of cracks varies in the interval (30-50) $\mathrm{mp}$. An important characteristic affecting the movement of gases from a fire seat is the rock permeability coefficient. The study of the aerodynamic characteristics of collapsed and deformed rocks at some mines in Kuzbass showed that the permeability coefficient varied from $5.8 \cdot 10^{-8}$ to $4.1 \cdot 10^{-10} \mathrm{~m}^{2}$. The gas filtration path ranged from 89 to $174 \mathrm{~m}$, the macro roughness index varied from $1.34 \cdot 10^{-9}$ to $7.2 \cdot 10^{-8} \mathrm{~m}$. Studies in laboratory conditions showed that the air permeability of bulk material varies from $10^{-6}$ to $10^{-8} \mathrm{~m}^{2}$. The permeability of the unloaded seam is about $10^{-12}$ $\mathrm{m}^{2}$.

The analysis of the obtained equation (4) shows that both in the absence of air filtration in the overlying rock layer and at excess gas pressure in the worked out space, the gases formed in the fire seat reach the surface in any case. The influence of the difference in gas pressure between the worked out space and the surface on the distribution pattern of these gases in the rocks was assessed for the case of the location of fire at a depth of $1000 \mathrm{~m}$. The air permeability coefficient of the rocks is $10-12 \mathrm{~m}^{2}$, the porosity is 0.3 . In the laminar 
regime of air filtration, the gas transfer rate was determined by equation (2). Carbon oxide with a molecular diffusion coefficient of $2 \cdot 10^{-5} \mathrm{~m}^{2} / \mathrm{s}$ was considered as an indicator gas. The distribution of the relative concentration of indicator gas in the overlying rocks at various drops of air pressure between the worked out space with the place of self-ignition and the atmosphere is shown in Fig. 1.

The analysis of the data given in Fig. 1 shows that with an excess air pressure in the worked out space equal to $1000 \mathrm{~Pa}$, there is a slight decrease in the concentration of indicator gas at a distance of about $750 \mathrm{~m}$ from the fire seat. Closer to the earth's surface there is a sharp decrease in gas concentration. Reducing excess air pressure to $400 \mathrm{~Pa}$ leads to a gradual decrease in the content of indicator gas in the overlying rocks.

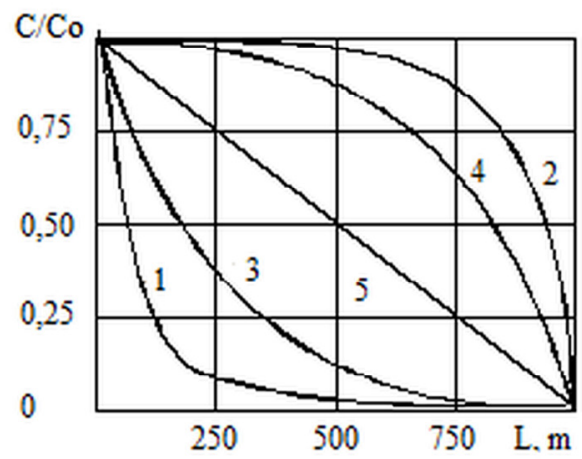

Fig. 1. Change in the relative concentration of the indicator gas in the rocks above the fire seat at various drops of air pressure: 1 -) $\mathrm{P}=-1000 \mathrm{~Pa} ; 2-$ ) $\mathrm{P}=+1000 \mathrm{~Pa} ; 3-$ ) $\mathrm{P}=-400 \mathrm{~Pa} ; 4-$ ) $\mathrm{P}=+400$ $\mathrm{Pa} ; 5-) \mathrm{P}=0 \mathrm{~Pa}$.

With the suction method of mine ventilation, which creates reduction of air pressure in the worked out space compared to atmospheric pressure, indicator gases may not reach the earth's surface. So, with an effective pressure of $-1000 \mathrm{~Pa}$, fire gases can be detected only at a depth of about $400 \mathrm{~m}$ from the surface. As depression decreases, the concentration of indicator gas increases and the distance of gases extension from the fire seat increases.

In the case of depth reduction of the fire seat and maintaining the magnitude of depression, the distance of the indicator gas distribution is also reduced. For example, at a fire seat depth of $200 \mathrm{~m}$ and an effective head of $-1000 \mathrm{~Pa}$, carbon oxide will propagate due to molecular diffusion only to a distance of $80 \mathrm{~m}$ from the fire seat.

With the spread of fire gases only due to molecular diffusion, a linear decrease in their concentration is observed on the way from the fire seat to the earth's surface. Therefore, the possibility of detecting these gases in the surface layer depends on the concentration of released gases in the fire seat, the distance from the fire seat to the measurement point and the sensitivity of used gas analysers. Figure 2 shows the influence of the distance between the fire seat and the measuring point on the concentration of this gas in the fire seat, which is necessary for its detection in the case of using instruments with a sensitivity of $0.0001 \%$. The calculation was made for a control point located at a depth of $1 \mathrm{~m}$ from the earth's surface. From the received results, it is clear that in order to detect the fire seat at a depth of $500 \mathrm{~m}$, the concentration of indicator gas in the area of the fire seat must be at least $0.05 \%$. 


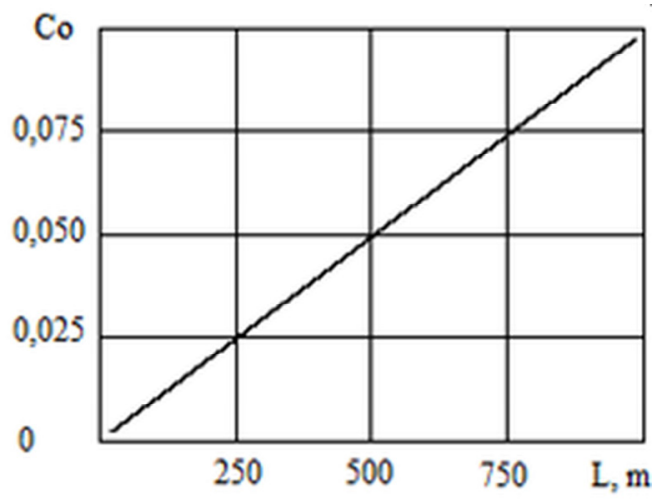

Fig. 2. Change in gas concentration in the fire seat, necessary for its detection in the soil, depending on the distance of the fire seat to the surface.

The calculation showed that the rock permeability increase affects ambiguously the concentration of gases formed in the fire seat in the near-surface layer. With excess air pressure in the worked out space, the increase in the rock permeability coefficient leads to an increase in the concentration of indicator gases in the surface layer. When the flow of filtered air flows from the earth's surface into the worked out space, which is possible for the suction method of ventilating the mine, an increase in the permeability of rocks helps to reduce the concentration of indicator gases in the overlying rock layer and the near-surface soil layer.

Effectiveness evaluation of the application of the method for determining the location of place of spontaneous combustion in the worked out space of mines according to the results of surface gas surveys was carried out at Kuzbass mines. At the same time, the distribution of the concentration of indicator gases in the surface layer was studied at different distances from the earth's surface.

The length of the investigated treatment field was $580 \mathrm{~m}, 17 \mathrm{~m}$ is upwards. The treatment works on the overlying horizons were carried out by a shield and chamber development systems. The seam thickness in this area is $10 \mathrm{~m}$, the incidence angle is $72^{\circ}$. The immediate seam roof is represented by mudstone of medium stability; the main is represented by sandstone. There are geological disturbances such as uplift with an amplitude of 3-4 m. The airing method is injection, in the area of the bridges isolating this excavation field; the effective pressure was 632 and $588 \mathrm{~Pa}$. There were air leaks. Alluviations are represented by clays with thickness of 5-15 m. Numerous holes were formed on the surface from mining operations, which were covered with local soil.

Because of signs of coal spontaneous combustion in an isolated field, a gas survey was conducted in the soil on a vertical projection of the excavation site onto the earth's surface. As a result of the survey, two anomalies of high-intensity fire gases (carbon oxide, hydrogen) were detected on the earth's surface (Fig. 3). One of the anomalies covers a large area above the shield pillars № 226, 230 and 235; the second anomaly is above the shield pillar № 257. Two low-intensity gas anomalies are located above the shield pillars № 254 and № 265 at the level of the haul roadway. Judging by the size of the anomalies and the concentration of fire gases in them, the first two anomalies testify the seats of endogenous fires, the second testify the seats of spontaneous combustion. 


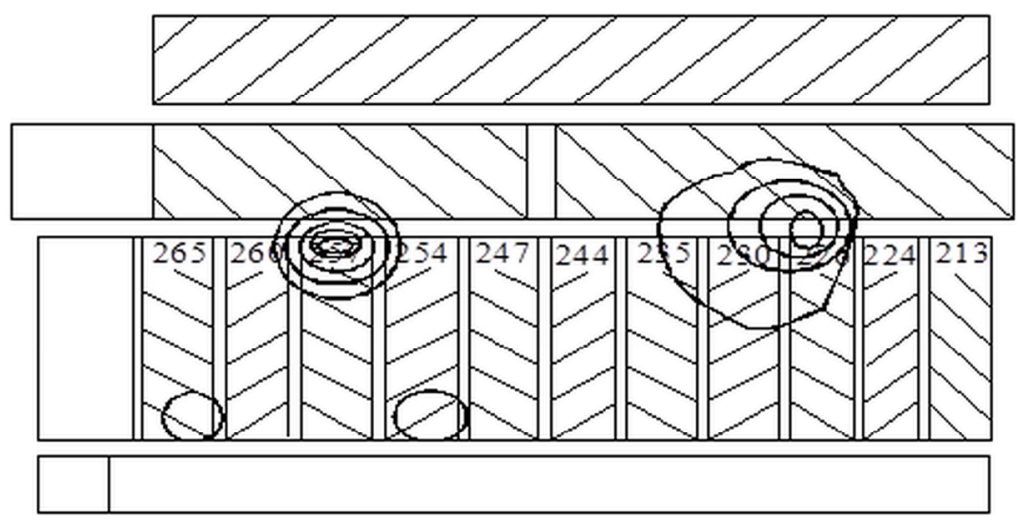

Fig. 3. Anomalies of fire gases over a worked out coal seam.

To study the distribution of fire gases concentration over the depth of the surface layer above the place of spontaneous combustion, a built-up pick was prepared with a maximum length of $3 \mathrm{~m}$. Measurements were taken over the second intense gas anomaly, over the shield 257. The pick was hollow, at its end, at a distance of $10 \mathrm{~cm}$, row of holes for sampling soil gases was drilled. As the pick deepened, gas samples were taken to determine the content of carbon oxide and hydrogen. The measurement results are given in table 1.

Table 1. The distribution of gas concentration in the depth of the surface layer.

\begin{tabular}{|c|c|c|c|c|c|c|}
\hline \multirow{2}{*}{ gas } & \multicolumn{6}{|c|}{ Well depth, m } \\
\cline { 2 - 7 } & $\mathbf{0 . 2}$ & $\mathbf{0 . 5}$ & $\mathbf{1 . 0}$ & $\mathbf{1 . 5}$ & $\mathbf{2 . 0}$ & $\mathbf{3 . 0}$ \\
\hline $\mathrm{CO}, \%$ & 0.0003 & 0.0019 & 0.0020 & 0.0021 & 0.0021 & 0.0023 \\
\hline $\mathrm{H}_{2, \%} \%$ & 0.0001 & 0.0005 & 0.0006 & 0.0006 & 0.0007 & 0.0007 \\
\hline
\end{tabular}

Table 1 shows that intense gas exchange is observed in the upper soil layer at a distance of 10-20 cm from the surface. Then, the concentration of gases released in the fire seat stabilizes and slightly increases with depth. The studies confirmed the results of mathematical modeling and the feasibility of wells drilling during gas surveys to a depth of $0.5-1.0 \mathrm{~m}$.

The detected endogenous fire was isolated by additional interlockings on the ventilation and haul roadway with the injection of inert materials into the space between them. However, the measures taken did not bring effect, so it was decided to use active extinguishing methods. In the wells drilled into the seam under the projection of a gas anomaly, signs of fire were detected, which confirmed the accuracy of determining the location of the fire seat by surface gas survey. Foam and a clay solution were supplied into the detected place of spontaneous combustion, which allowed to localize and then eliminate the fire seat.

\section{Conclusions}

The conducted studies allow us to draw the following conclusions.

1. The place of spontaneous combustion occurring in the worked out space of mines can form a concentration field of the evolved gases, which can form anomalies on the earth's surface.

2. The removal of fire gases to the earth's surface is facilitated by molecular diffusion and thermal depression, developed by the place of spontaneous combustion, as well as excessive air pressure in a mine, created by the operation of ventilation fans. 
3. An anomaly of fire gases on the earth's surface is a vertical projection of the underground fire seat; therefore, a surface gas survey allows you to determine the location of the fire in a worked out mine.

4. To determine the location of the underground fire seat by conducting a surface gas survey, it is enough to measure the content of fire gases in the soil at a depth of 0.5-1.0 m.

5. Mine observations confirmed the effectiveness of the detection and location of endogenous fire seats in mines by conducting surface gas surveys.

\section{References}

1. M. J. Gouws, G. J. Gibbon, L. Wade, H. R. Phillips, Mining Science and Technology, 13(3), 417, (1991)

2. B. Genc, A. Cook, Journal of the Southern African Institute of Mining and Metallurgy, 115(7), 563 (2015)

3. E. Kaymakçi, V. Didari, Turkish Journal of Engineering and Environmental Sciences, 26(1), 59 (2002)

4. B. B. Beamish, G. R. Hamilton, International Journal of Coal Geology, 64(1-2), 133 (2005)

5. R. Morris, T. Atkinson, Mining Science and Technology, 7(2), 149 (1988)

6. V. A. Portola, Journal of Mining Science, 32(6), 536, (1996)

7. A. H. Ozdeniz, O. Sivrikaya, S. Kelebek, Energy Sources, Part A: Recovery, Utilization and Environmental Effects, 37(19), 2114 (2015)

8. K. Brooks, D. Glasser, Fuel, 65(8), 1035 (1986)

9. Q. Lin, S. Wang, S. Song, Y. Liang, T Ren, Fuel Processing Technology, 159, 38 (2017)

10. V. Portola, A. Bobrovnikova, A. Shirokolobova, E3S Web of Conference, 105, 01037 (2019)

11. Y. Liang, J. Zhang, L. Wang, H. Luo, T. Journal of Loss Prevention in the Process Industries, 57, 208 (2019)

12. K. Wojtacha-Rychter, A. Smoliński, Fuel, 233, 37 (2018)

13. K. Wojtacha-Rychter, A. Smoliński, International Journal of Coal Geology, 202, 38 (2019)

14. L. Snopek, A. Adamus, J. Sancer, Journal of Mines, Metals and Fuels, 60, 193 (2012)

15. H. Wen, Z. Yu, S. Fan, X. Zhai, W Liu, Combust. Sci. Technol., 189, 1713 (2017)

16. V. A. Portola, E. S. Torosyan, V. K. Antufeyev, IOP Conference Series: Materials Science and engineering, 127, 02013 (2016) 